\title{
Pareto fronts-driven Multi-Objective Cuckoo Search for 5G Network Optimization
}

\author{
Junyan Wang ${ }^{1}$ \\ ${ }^{1}$ School of Computer Science \& Technology, \\ Taiyuan University of Science and Technology, Taiyuan, Shanxi, China \\ [e-mail: JunYanWang@tyust.edu.cn] \\ *Corresponding author: Junyan Wang
}

Received February 24, 2020; revised April 4, 2020; accepted May 30, 2020; published July 31, 2020

\begin{abstract}
5G network optimization problem is a challenging optimization problem in the practical engineering applications. In this paper, to tackle this issue, Pareto fronts-driven Multi-Objective Cuckoo Search (PMOCS) is proposed based on Cuckoo Search. Firstly, the original global search manner is upgraded to a new form, which is aimed to strengthening the convergence. Then, the original local search manner is modified to highlight the diversity. To test the overall performance of PMOCS, PMOCS is test on three test suits against several classical comparison methods. Experimental results demonstrate that PMOCS exhibits outstanding performance. Further experiments on the 5G network optimization problem indicates that PMOCS is promising compared with other methods.
\end{abstract}

Keywords: Cuckoo search, Pareto fronts,Convergence, Diversity, 5G Network Optimization 


\section{Introduction}

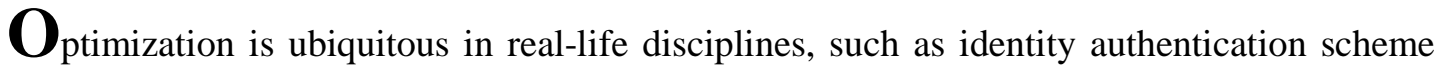
optimization[1], breast cancer classification[2,3], wireless sensor network optimization[4], personalized recommendation system[5], water resource optimization[6], and so on. The purpose of optimization is to find the best solution to an optimization problem[7,8]. General optimization algorithms include three categories: evolutionary algorithms, swarm-based algorithms and trajectory-based algorithms. CS[9] is a typical swarm-based method, which has gained a lot of attentions since it was published. Up to now, many variants of CS have been proposed for various purposes, which can be summarized as follows:

Theoretical research on various forms is the first category. Binary CS algorithms have been published in many papers. To tackle binary optimization, Gherboudj et al.[10] designed a discrete binary CS, where cuckoos are represented with a family of bits. Binary CS can be applied to many practical issues, such as multiple destination routing problem[11], job shop scheduling[12], and flow-shop scheduling problems[13]. Discrete cuckoo search is next research topic. Travelling Salesman Problem(TSP)[14] is a popular benchmark problem, which requires salesman to return to finishing point with minimal trip length. To tackle this TSP, Ouyang et al.[15] designed a discrete version of CS, where all individuals are located on the surface of a sphere. Also for TSP, Jati et al.[16] proposed two-phase discrete cuckoo search algorithm, including discrete step size and a random step length. Combining CS with other effective strategies is another research aspect. Abdul et al. [17] incorporated roulette wheel and inertia weight strategies to CS for strengthening the search ability. To improve the convergence, Giridhar et al.[18] introduced crossover operation to CS.

Hybridizing CS with other strategies is the second category, which is able to make up the drawbacks of CS, as well as incorporating the advantage of CS to other methods. Genetic algorithm(GA) is a popular method, which has shown great search ability. To redundancy allocation problems, Kanagaraj et al.[19] designed a version of CS with GA by integrating genetic operator CS. Further, Kanagaraj et al.[20] empirically proved the efficiency of the combination of CS and GA. The advantage of differential evolution lies in exploring the search space. Wang et al.[21] proposed to strengthen CS by embedding DE to CS. Nancharaiah et al.[22] designed a hybrid technique combining CS and Ant Colony Optimization (ACO), where ACO is responsible to update the pheromone, while CS is used as a local search method.

In terms of application of CS, many papers have been reported. In medical domain, to determine the best parameter settings, Liu et al.[23,24] employed CS to optimize the initial parameter of the kernel function of support vector machine(SVM). To diagnose diabetes, Giveki et al.[25,26,27] proposed a novel approach, which mainly combined SVM and CS. To increase the cover rate of c-means defect in medical image segmentation, Manikandan et al.[28] utilized CS and PSO to achieve quick convergence. In information retrieval domain, finding relevant information is of great importance. To clearly organize and summarize the retrieval information, Zaw et al.[29] proposed a cuckoo search clustering method. To extract meaningful section of satellite image, Bhandari et al.[30] incorporated CS to wind-driven optimization algorithm by introducing Kapur's entropy.

In this paper, to tackle a 5 G network optimization problem [31,32], Pareto fronts-driven Multi-Objective Cuckoo Search(PMOCS) is proposed. Then three test suits are used to verify the proposed method. Then, the 5G network optimization problem is tackled with the 
proposed method. Thus, according to the summaries above, this paper falls into the third categories. The highlights of this paper are presented as follows:

1) Firstly, this paper proposed a multi-objective version of CS. To upgrade CS, this paper redesigns the global search manner and local search equation. Moreover, the meanings behind each upgrade are also explained.

2) To assess the proposed method, this paper utilizes two popular test suits in later experiment, as well as several comparison methods. Detailed experimental results, including tables and figures, are presented and analyzed.

3) Further, this paper applies PMOCS to a 5G network optimization. Experimental results are analyzed to show the superiority of PMOCS.

This paper is originazed as follows. Basic definitions and related work are introduced in Section 2. Following that, PMOCS is detailed in section 3. In next section, two experiments are conducted, including an empirical verification on benchmark problem and the 5G network optimization problem.

\section{Preliminaries}

\subsection{Basic definitions}

Generally, typical multi-objective optimization problems(MOPs) $[4,33,34]$ have two or three objectives, which are formulated with the following expression:

$$
\begin{aligned}
\min F(x) & =\left[f_{1}(x), f_{2}(x), \ldots, f_{M}(x)\right] \\
x & =\left(x_{1}, x_{2}, \ldots, x_{D}\right) \in R^{D}
\end{aligned}
$$

where $f_{M}(x)$ indicates the $M$-th sub-objective function, $x$ means the decision vector.

For solution $x_{1}$ and $x_{2}, x_{1}$ dominates $x_{2}$ if and only if $\forall i \in\{1,2,3, \ldots, M\}$ : $f_{i}\left(x_{1}\right) \leq f_{i}\left(x_{2}\right), \exists i \in\{1,2,3, \ldots, M\}: f_{i}\left(x_{1}\right)<f_{i}\left(x_{2}\right)$.The domination relationship between $x_{1}$ and $x_{2}$ can be expressed as $x_{1} \prec x_{2}$.

\subsection{Related Work}

CS[9], as a typical swarm-based method, mainly mimics the breeding behavior of cuckoo. Cuckoo is able to intelligently choose host's nests to lay their eggs. Usually, Offspring have higher survival rates. Yang et al.[9] abstracts these behaviors with the following formulations.

Assuming $X_{i}$ is the position of cuckoo $i, X_{i}$ is updated with the following global update manner:

$$
X_{i}\left(t^{\prime}\right)=X_{i}(t)+\alpha \oplus \operatorname{Levy}(\lambda)
$$

where $\oplus$ means entry-wise multiplications and $\alpha>0$ indicates the step size, which is defined with following equation:

$$
\alpha=\alpha_{0} \times\left(X_{i}(t)-X_{\text {best }}\right)
$$

where $\alpha_{0}=0.01, X_{\text {best }}$ indicates the global best position in current population.

$\operatorname{Levy}(\lambda)$ in Eq.(2) satisfies Eq.(4):

$$
\operatorname{Levy}(\lambda) \sim \mu=t^{-\lambda}
$$

where $1<\lambda<3$. 
However, the egg lay by cuckoo $i$ is generally discovered and abandoned with probability $p_{a}$.In this case, new egg should be lay again with the following manner:

$$
X_{i}(t+1)=X_{i}\left(t^{\prime}\right)+r \times\left(X_{k}\left(t^{\prime}\right)-X_{j}\left(t^{\prime}\right)\right)
$$

where both $X_{k}\left(t^{\prime}\right)$ and $X_{j}\left(t^{\prime}\right)$ present two random cuckoo birds. $r$ indicates a random value in $\left[\begin{array}{ll}0 & 1]\end{array}\right.$.

The flowchart of CS is expressed with Fig. 1.

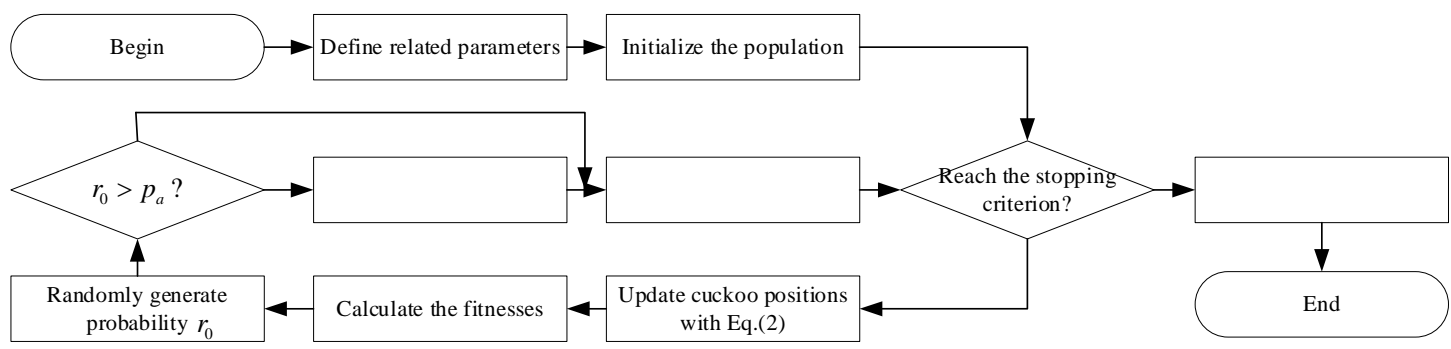

Fig. 1. Flowchart of CS

Obviously, CS is originally designed for single-objective optimization problems because the global best in Eq.(2) does not exist in multi-objective optimization problems (MOPs) [35,36,37], instead of Pareto sets. Over the past decades, numerous researchers are dedicated to apply CS to MOPs. For example, Hanoun et al.[38] designed a Pareto archived multi-objective CS to tackle a multi-objective job shop scheduling problem. Zhang et al.[39] proposed a multi-objective CS by introducing a non-dominated sorting strategy and a dynamical local search strategy to CS. Coelho et al.[40] employed the nearest neighbor density estimation method to redesign CS for MOPs. Wang et al.[41] incorporated the non-dominated sorting strategy of NSGA-II into CS for tackling optimal design of water distribution system. To solve multi-objective community detection problem, Zhou et al.[42] redefined a location update strategy and a abandon operator in discrete form. To optimize the heat transfer in plate-finheat exchangers, Wang et al.[43] designed a non-uniform mutation operator and a differential evolution operator to strengthen the convergence of CS. To extend CS to multi-objective problems with more than three objectives, Cui et al.[44] proposed to update each dimension of each cuckoo with different probabilities.

As no-free lunch theorem[45] points out, no one method performs the best on all kinds of problems. Although various multi-objective CS[39,46,47] have been proposed and have exhibited outstanding performance in practical problems, they may be not suitable to the 5G network optimization problem[31]. Therefore, this paper specially designs a Pareto fronts-driven Multi-Objective Cuckoo Search algorithm (PMOCS).

\section{Proposed method}

In MOPs, there generally exist multiple Pareto fronts due to the conflict nature of various objectives. In principle, the former Pareto front is better than the later Pareto front regarding the convergence. Thus, to utilize the leading information inspired from the different Pareto fronts, the global manner is upgraded with Eq.(6):

$$
X_{i}\left(t^{\prime}\right)=X_{i}(t)+0.01 \times \alpha \times L \times r_{G} \times\left(X_{k}(t)-X_{j}^{\text {later }}(t)\right)
$$


where $\alpha=1.0, L$ is generated with Levy distribution. $r_{G}$ follows the standard Gaussian distribution. Both $X_{k}(t)$ and $X_{i}(t)$ come from the same Pareto front, while $X_{j}^{\text {later }}(t)$ comes from the Pareto front which is inferior to $X_{k}(t)$ 's Pareto front.

The reason for designing Eq.(6) can be illustrated with Fig. 2. Assuming there are two Pareto fronts in objective space, individual $P_{1}$ and $P_{2}$ belong to the first and second Pareto front, respectively. It can be said that $P_{1}$ is superior to $P_{2}$ in terms of convergence. Thus, $P_{1}-P_{2}$ is able to provide the leading information to individuals to be updated as the arrow in Fig. 2 shows. In other words, $P_{1}-P_{2}$ is used to facilitate the convergence by providing the convergent information.

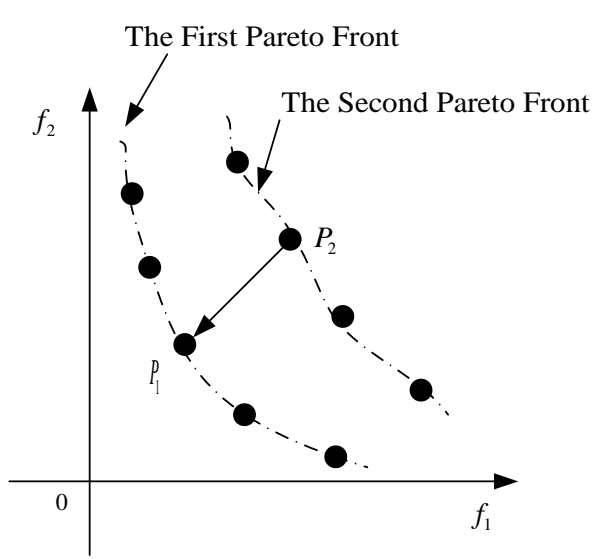

Fig. 2. Illustration of Eq.(6)

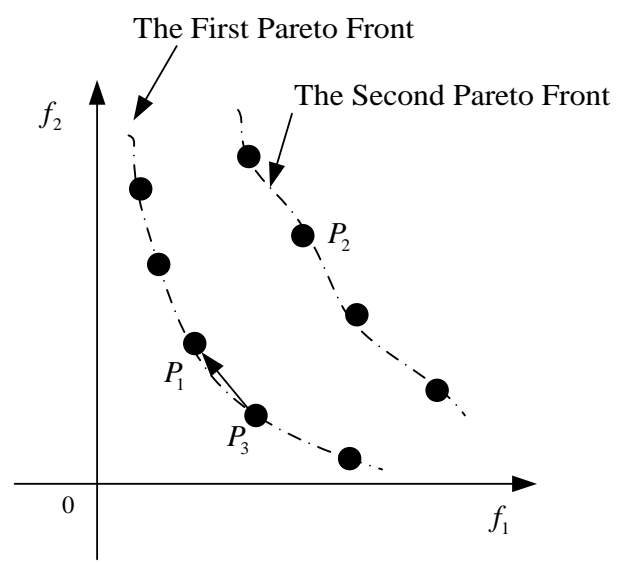

Fig. 4. Illustration of Eq.(7)

The local search manner is upgraded as follows:

$$
X_{i}(t+1)=X_{i}\left(t^{\prime}\right)+r \times\left(X_{k}\left(t^{\prime}\right)-X_{j}^{s}\left(t^{\prime}\right)\right)
$$

where both $X_{k}\left(t^{\prime}\right)$ and $X_{j}\left(t^{\prime}\right)$ come from the first Pareto front. Note that, to further strengthen the diversity in later search stage, this paper employs a tournament selection strategy to generate $X_{k}\left(t^{\prime}\right)$ and $X_{j}\left(t^{\prime}\right)$. For completeness, the basic framework of the tournament selection strategy is presented in Fig. 3.

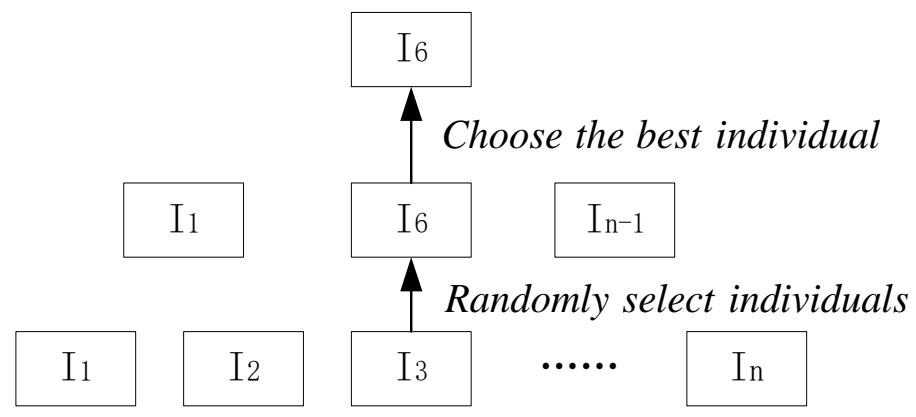

Fig. 3. Illustration of tournament selection strategy 
Eq.(7) is used to strengthen the diversity. As illustrated in Fig. 4. Let $P_{1}$ and $P_{3}$ be two individuals from the first Pareto front, $P_{1}-P_{3}$ indicates the black arrow, which means individuals will be guided to search more diverse potential sections.

Updating population is a vital operation which can ensure that high-quality cuckoos pass to the next generation. PMOCS employs the non-dominated sorting strategy and crowding distance[48,49,50] to update the population. As Fig. 5 exhibits, parent population $P_{t}$ and offspring population $Q_{t}$ are firstly merged into one population $P_{t} \cup Q_{t}$ of $2 N$ cuckoos. After that, the non-dominated sorting strategy is used to divide $P_{t} \cup Q_{t}$ into multiple Pareto fronts. Then, $N$ cuckoos are selected from the $P_{t} \cup Q_{t}$. Note that, if only partial cuckoos in certain Pareto front are included into the next generation, the crowding distance is used as the indicator to measure each individual's crowding degrees. Less crowded individuals are preferred and included into the next generation.

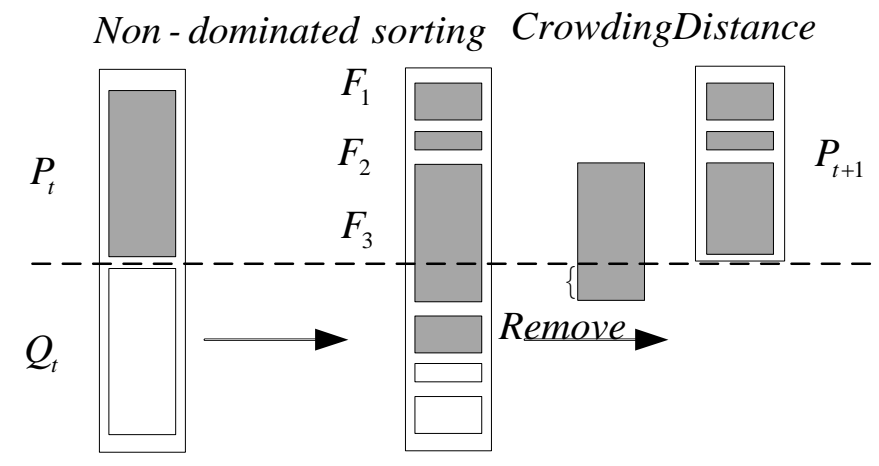

Fig. 5. Illustration of population update

The flowchart of PMOCS is presented in Fig. 6. As can be seen, firstly, the population is initialized after defining the related paramters, such as the discover probability. Then, Cuckoo popistions are updated with Eq.(6) if the stopping criterion is not reached. After that, some cuckoo positions are updated with Eq.(7). Following that, the resultant cuckoos are updated in combintion with previous cuckoos for the next generation. If the stopping criterion is not reached, repeat the procedures above. Otherwiese, output the Pareto set.

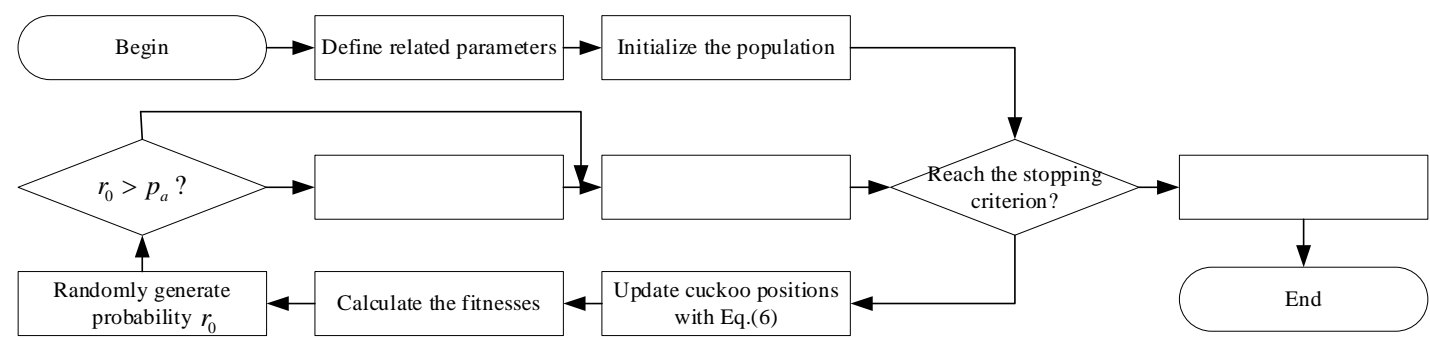

Fig. 6. Flowchart of PMOCS 


\section{Experimental Results and Analysis}

The section is divided into two experiments. One experiment is to verify PMOCS with benchmark problems, and the second one is to apply PMOCS to the 5G network optimization problem. Before that, experimental settings are introduced.

\subsection{Experimental settings}

To verify PMOCS, various methods, including HMOCS[39], NSGA-II[48], NNIA[51] and MOPSO[52] are used as comparison algorithms. All parameters related to comparison methods are presented in Table 1, which follow the settings of original papers. The performance indicator is IGD[53], which is able to measure both the convergence and diversity. The test suites are ZDT[54], DTLZ[55] and MaF[56], all of which are presented in Table 2. The discover probability $p_{a}$ is set to 0.3 . All algorithms run 20 times.

Table 1. Parameter settings

\begin{tabular}{|c|l|}
\hline Method & \multicolumn{1}{|c|}{ Parameter } \\
\hline NNIA & $N a=20, n C=100$ \\
\hline HMOCS & $p_{a}=0.25, r=$ rand \\
\hline MOPSO & div $=10$ \\
\hline PMOCS & $p_{a}=0.3$ \\
\hline NSGA-II & $p_{c}=1, p_{m}=1 /$ dimension. \\
\hline
\end{tabular}

Table 2. Illustration of test problems

\begin{tabular}{|c|c|c|c|}
\hline Problem & Objective & Dimension & Maximum Iteration \\
\hline ZDT1 & 2 & 30 & 100 \\
\hline ZDT2 & 2 & 30 & 100 \\
\hline ZDT3 & 2 & 30 & 100 \\
\hline ZDT4 & 2 & 10 & 100 \\
\hline DTLZ1 & 3 & 7 & 700 \\
\hline DTLZ2 & 3 & 12 & 250 \\
\hline MaF1 & 3 & 12 & 100 \\
\hline MaF2 & 3 & 12 & 100 \\
\hline
\end{tabular}

\subsection{Experimental results and analysis}

Table 3 exhibits the experimental results, where the best values are highlighted in boldface. The values in parentheses are variances. From Table 3, we can observe that PMOCS perform better on all test instances except ZDT2 and MaF2. On ZDT2, PMOCS is obviously inferior to NSGA-II. On MaF2, although PMOCS is slightly worse than HMOCS, there is no evident difference between them. Therefore, PMOCS is empirically better than other comparison methods.

Table 3. Comparison of experimental results

\begin{tabular}{|c|c|c|c|c|c|}
\hline Problem & PMOCS & HMOCS & NSGA-II & NNIA & MOPSO \\
\hline ZDT1 & $\mathbf{1 . 5 3 5 2 e - 1 ~ ( 7 . 8 3 e - 2 )}$ & $2.1845 \mathrm{e}-2(6.88 \mathrm{e}-3)$ & $1.5728 \mathrm{e}-1(9.11 \mathrm{e}-2)$ & $1.6697 \mathrm{e}-1(4.41 \mathrm{e}-2)$ & $5.0737 \mathrm{e}+1(5.07 \mathrm{e}-1)$ \\
\hline ZDT2 & $6.0331 \mathrm{e}-1(1.32 \mathrm{e}-1)$ & $3.7422 \mathrm{e}-2(2.99 \mathrm{e}-3)$ & $\mathbf{3 . 7 3 2 9 e - 1} \mathbf{( 2 . 5 8 e - 1 )}$ & $6.0098 \mathrm{e}-1(1.62 \mathrm{e}-1)$ & $5.1458 \mathrm{e}+1(2.99 \mathrm{e}+0)$ \\
\hline ZDT3 & $\mathbf{1 . 9 1 2 3 e - 1 ~ ( 1 . 3 0 e - 1 )}$ & $1.9132 \mathrm{e}-1(8.01 \mathrm{e}-4)$ & $2.1955 \mathrm{e}-1(1.61 \mathrm{e}-1)$ & $1.9755 \mathrm{e}-1(1.49 \mathrm{e}-1)$ & $4.0852 \mathrm{e}+1(1.06 \mathrm{e}+1)$ \\
\hline ZDT4 & $\mathbf{1 . 7 6 5 2 e - 1}(\mathbf{1 . 0 1 e - 1})$ & $5.7738 \mathrm{e}+0(1.52 \mathrm{e}+0)$ & $2.7733 \mathrm{e}-1(7.60 \mathrm{e}-2)$ & $1.7879 \mathrm{e}-2(2.16 \mathrm{e}-3)$ & $1.8461 \mathrm{e}+1(4.11 \mathrm{e}+0)$ \\
\hline DTLZ1 & $\mathbf{2 . 0 1 2 6 e - 2}(\mathbf{4 . 4 9 e}-3)$ & $2.3294 \mathrm{e}-2(1.61 \mathrm{e}-4)$ & $2.6706 \mathrm{e}-2(6.22 \mathrm{e}-4)$ & $2.7550 \mathrm{e}-2(1.01 \mathrm{e}-3)$ & $4.5615 \mathrm{e}+0(1.90 \mathrm{e}+0)$ \\
\hline
\end{tabular}




\begin{tabular}{|c|c|c|c|c|c|}
\hline DTLZ2 & 5.4273e-2 (3.29e-4) & $7.5090 \mathrm{e}-2$ (9.44e-4) & 7.0060e-2 (5.83e-4) & $6.9691 \mathrm{e}-2$ (4.07e-3) & $1.3433 \mathrm{e}-1$ (2.72e-2) \\
\hline MaF1 & 4.1999e-2 (2.67e-4) & $4.3399 \mathrm{e}-2$ (3.63e-4) & $5.8512 \mathrm{e}-2$ (1.28e-3) & $6.0241 \mathrm{e}-2$ (2.03e-3) & $7.5870 \mathrm{e}-2$ (3.07e-3) \\
\hline MaF2 & $3.3249 \mathrm{e}-2$ (1.16e-3) & $\mathbf{3 . 1 9 3 9 e - 2 ~ ( 2 . 1 9 e - 3 )}$ & $5.0499 \mathrm{e}-2$ (7.55e-4) & $5.4751 \mathrm{e}-2$ (5.05e-3) & $4.6688 \mathrm{e}-2$ (6.68e-3) \\
\hline
\end{tabular}
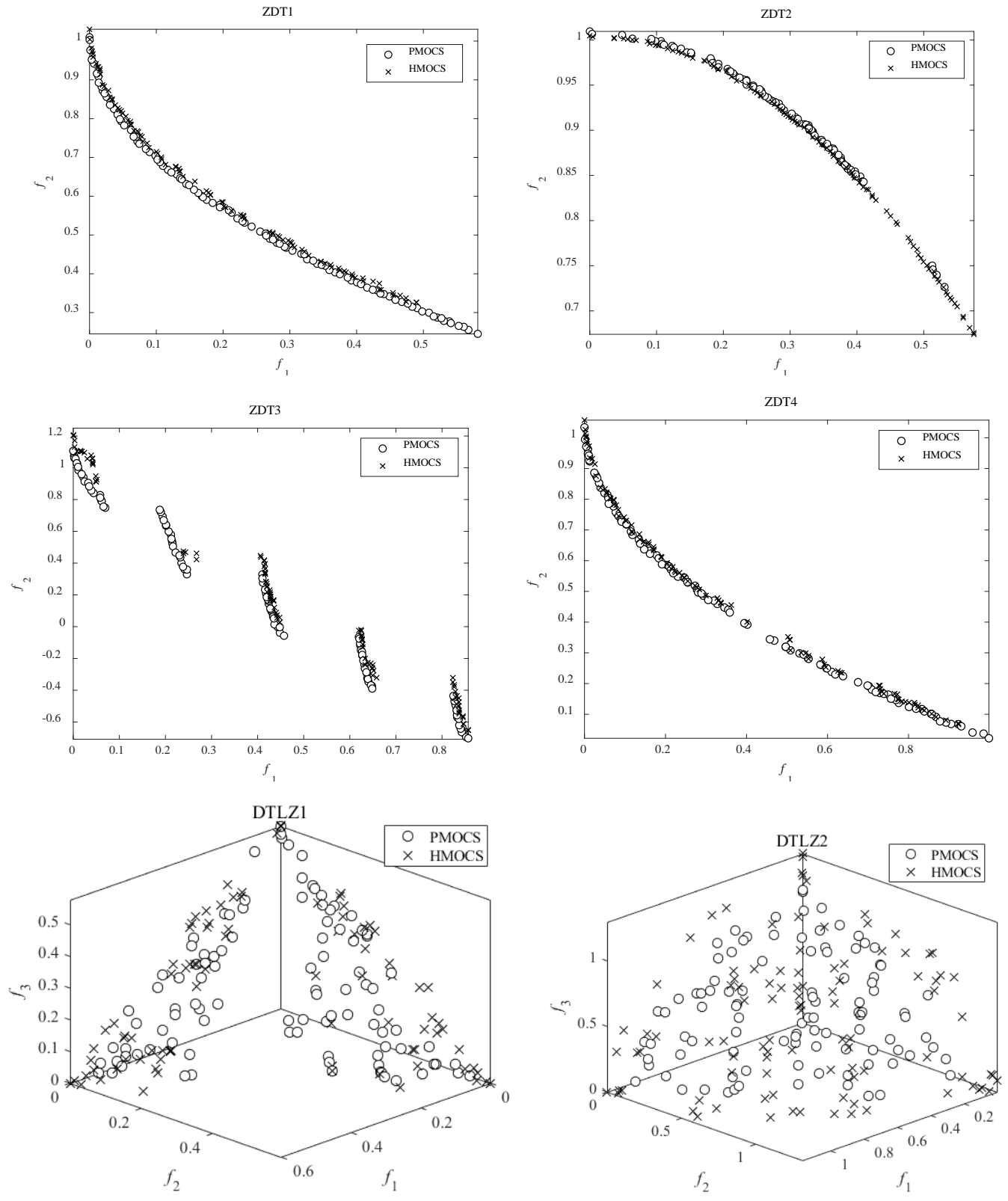

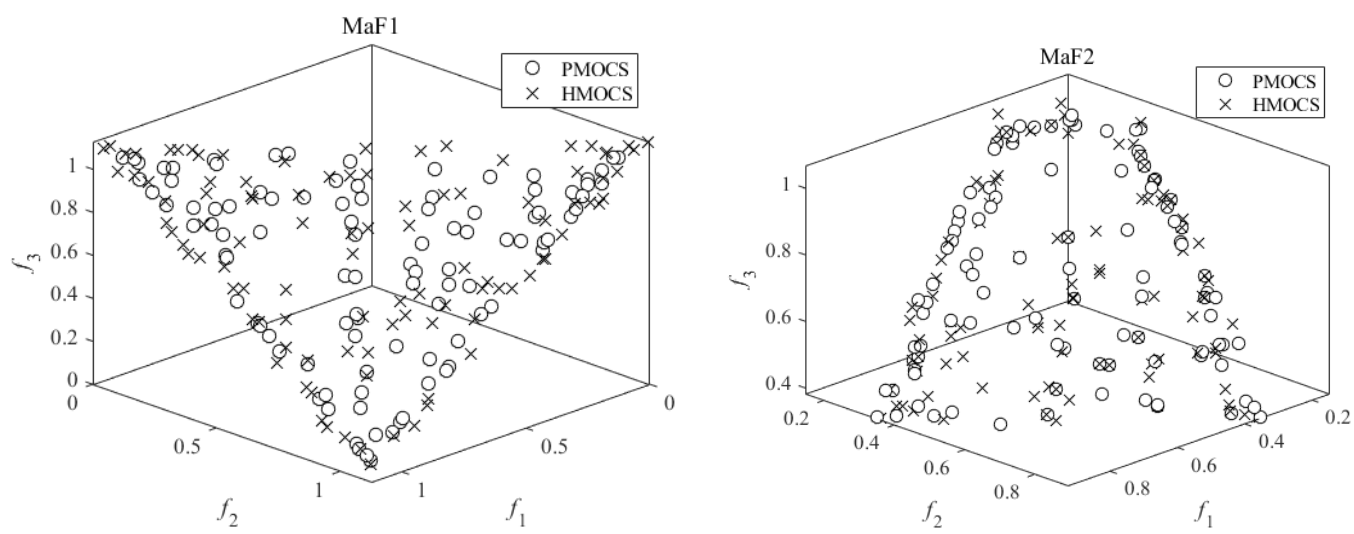

Fig. 7. Comparison of Pareto fronts on test problems

Fig. 7 presents the comparison of Pareto fronts obtained by PMOCS and HMOCS on all test problems. It can be seen that there is not obvious differences on ZDT1, ZDT4, DTLZ1, MaF1 and MaF2. Regarding ZDT2 and ZDT3, PMOCS is evidently superior to HMOCS because certain regions are missing for HMOCS. On DTLZ2, the fact can be seen that PMOCS is better than HMOCS regarding the convergence.

\subsection{G Network Optimization}

More convenient cellular networks is coming with the introduction of 5G networks. Over the past few decades, various methods have been proposed in the technological preparations for $5 \mathrm{G}$ network. Massive multiple-input multiple-output (MIMO) system is one of key enabler of 5G network. Massive MIMO is proposed based on the idea of deploying large arrays with a lot of active antennas at base stations (BSs) and serve limited number of users. Massive MIMO is robust to the distortions caused by hardware imperfections[57].

The aim of this section is to optimize the downlink transmission of a missive MIMO system[21], which has two conflicting objectives, high average user rates and high energy efficiency. As Fig. 8 shows, assume there are $N$ antennas and $K$ single-antenna users. $B=10 \mathrm{MHz}$ indicates the bandwidth. The emitted power per BS is $P$ Watt. $\sigma^{2}=10^{-13} \mathrm{~W}$ is the average noise power. The size of each cell is $250 \times 250$ meters. That is to say, $A=0.25^{2} \mathrm{~km}^{2}$.

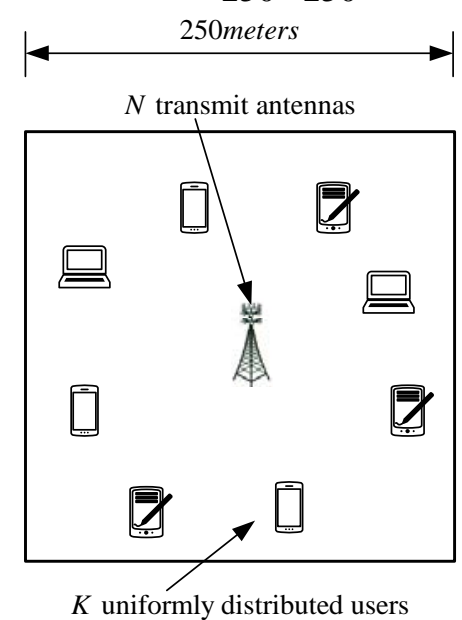

Fig. 8. Illustration of missive MIMO system 
Average user rate $\left(f_{1}\right)$ and energy efficiency $\left(f_{2}\right)[58]$ are defined with the following equations:

$$
\left\{\begin{array}{l}
f_{1}=B\left(1-\frac{K}{\Upsilon}\right) \log _{2}\left(1+\frac{\frac{P}{K}(N-K)}{\sigma^{2} \Lambda_{1}+P \Lambda_{2}}\right) \\
f_{2}=\frac{K \times f_{1}}{P_{\text {total }}} \\
\text { s.t. } P_{\text {total }}=\frac{P}{\eta}+N C_{N}+K C_{K}+\frac{C_{\text {precoding }}}{L}+C_{0}
\end{array}\right.
$$

where $\Lambda_{1}=1.72 \times 10^{9}, \Lambda_{2}=0.54$ [59], $C_{N}=0.5 \mathrm{~W}, C_{K}=0.3 \mathrm{~W}, C_{0}=10 \mathrm{~W}$, $C_{\text {precoding }}=3 K^{2} N \frac{B}{\Upsilon}, L=12.8 G$ flops $/ W$. From Eq.(8), it can be seen that the average user rate should be as high as possible, while energy efficiency should be as low as possible.

The variables to be optimized are $K, N$ and $P$, and they follows the following constraints:

$$
\begin{aligned}
& x=\left[\begin{array}{lll}
K & N & P
\end{array}\right] \\
& \text { s.t. }\left\{\begin{array}{l}
1 \leq K \leq \frac{N}{2} \\
2 \leq N \leq N_{\text {max }} \\
0 \leq P \leq N P_{\text {max }}
\end{array}\right.
\end{aligned}
$$

where $N_{\max }=500$ and $P_{\max }=20 \mathrm{~W}$.

To test the performance of PMOCS on practical problems, PMOCS, HMOCS, NNIA, NSGA-II and MOPSO are applied to the 5G network optimization. All the parameters remains the same as illustrated above. Maximal iteration is set to 2000. Fig. 9 plots the comparison results.
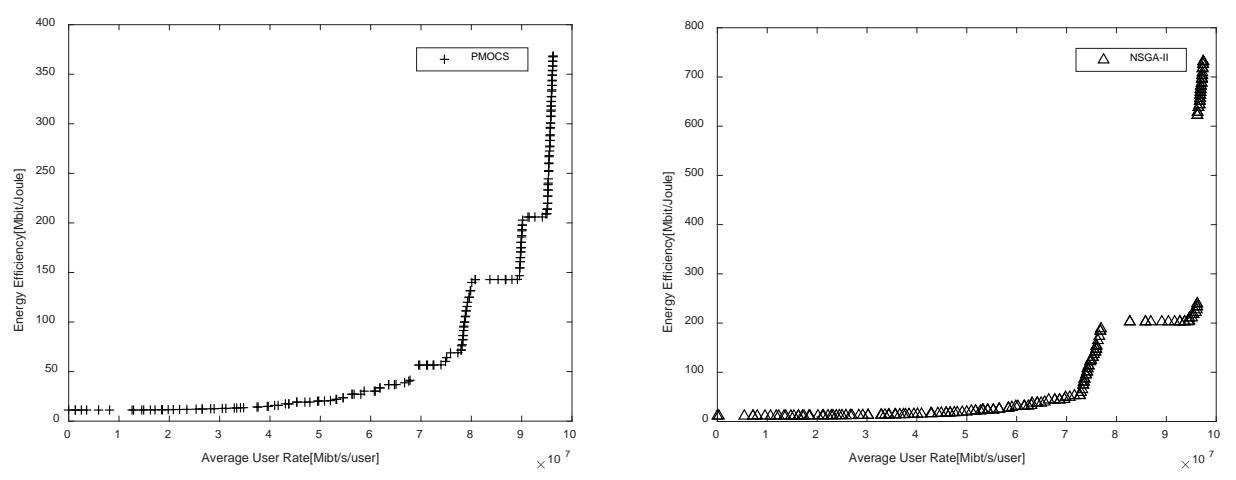

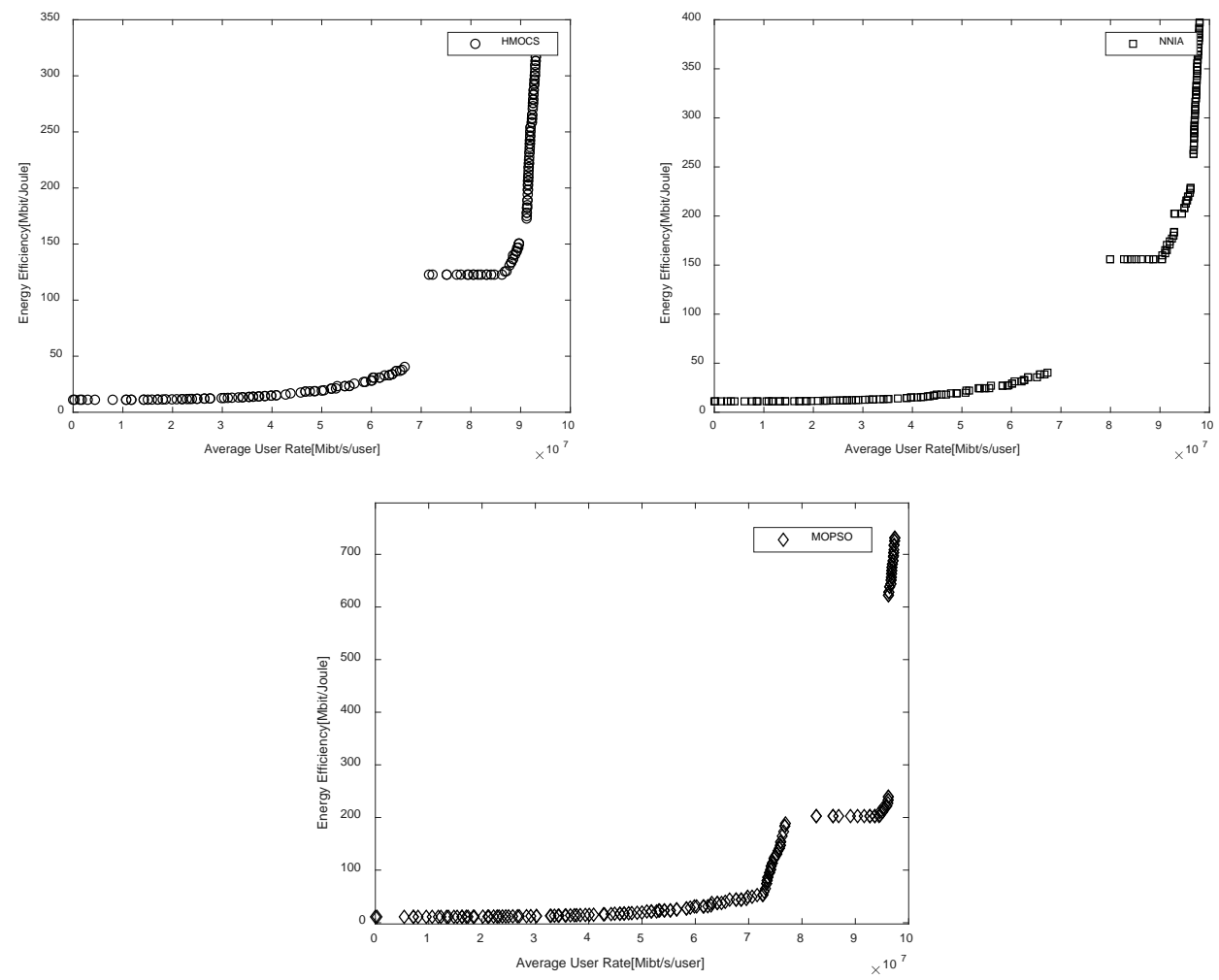

Fig. 9. Comparison of experimental results on the $5 \mathrm{G}$ network optimization problem

From Fig. 9, we can observe that the Pareto front obtained by PMOCS is able to cover the most area. However, compared with PMOCS, NSGA-II performs less satisfied due to the discontinuous Pareto front. Further, HMOCS is relatively better than NNIA and MOPSO in terms of final Pareto fronts. In summary, PMOCS is empirically promising in tackling practical problems.

\section{Conclusion}

In this paper, to tackle the $5 \mathrm{G}$ network optimization problem, PMOCS is proposed. This paper firstly upgrades the global search manner to a new version, which is able to generate the evolutionary pressure to the ideal Pareto front. Then, the local search manner is improved to guide the population to various promising areas. The experimental results on three test suits show that PMOCS is better than other comparison methods. Further, the experiment results on the 5G network optimization problem demonstrate that PMOCS is more effective in comparison with other methods. Next work will concentrate on the further improvement of PMOCS.

\section{References}

[1] Z. Cui, F. Xue, S. Zhang, X., Y. Cao, W. Zhang and J. Chen, “A Hybrid Block Chain-Based Identity Authentication Scheme for Multi-WSN,” IEEE Transactions on Services Computing, vol.13, pp.241-251, 2020. Article (CrossRef Link) 
[2] M. N. Sudha, S. Selvarajan and M. Suganthi, "Feature selection using improved lion optimisation algorithm for breast cancer classification,” International Journal of Bio-Inspired Computation, vol. 14, 2019. Article (CrossRef Link)

[3] Z. Shen, Y. Niu; Y. Zuo, Q. Xie and Z. Chen, "Power control of wind energy conversion system under multiple operating regimes with deep residual recurrent neural network: theory and experiment,” International Journal of Computing Science and Mathematics, vol. 10, 2019. Article (CrossRef Link)

[4] X. Cai, P. Wang, L. Du, Z. Cui, W. Zhang and J. Chen, "Multi-objective 3-Dimensional DV-Hop Localization Algorithm with NSGA-II,” IEEE Sensors Journal, vol.19, no.21, pp.10003-10015, 2019. Article (CrossRef Link)

[5] Z. Cui, X. Xu, F. Xue, X. Cai, Y. Cao, W. Zhang and J. Chen, "Personalized Recommendation System based on Collaborative Filtering for IoT Scenarios,” IEEE Transactions on Services Computing, pp. 1-1, 2020. Article (CrossRef Link)

[6] H. Wang, W. Wang, Z. Cui, X. Zhou, J. Zhao and Y. Li, “A new dynamic firefly algorithm for demand estimation of water resources,” Information Sciences, vol. 438, pp.95-106, 2018. Article (CrossRef Link)

[7] X. Cai, H. W., Z. Cui, J. Cai, Y. Xue and L. Wang, "Bat algorithm with triangle-flipping strategy for numerical optimization,” International Journal of Machine Learning and Cybernetics, vol.9, no.2, pp.199-215, 2018. Article (CrossRef Link)

[8] B. Niu, J. Liu, and L. Tan, "Multi-swarm cooperative multi-objective bacterial foraging optimization,” International Journal of Bio-Inspired Computation, vol. 13, pp. 21-31, 2019. Article (CrossRef Link)

[9] X. Yang and S. Deb, "Cuckoo search via Levy flights," in Proc. of World Congress on Nature and Biologically Inspired Computing, India, pp.210-214, 2009. Article (CrossRef Link)

[10] A. Gherboudj, A. Layeb and S. Chikhi, "Solving 0-1 knapsack problems by a discrete binary version of cuckoo search algorithm,” International Journal of Bio-Inspired Computing, vol.4, no.4, pp.229-236, 2012. Article (CrossRef Link)

[11] Z. Zhan and J. Zhang, "Discrete particle swarm optimization for multiple destination routing problems," in Proc. of Workshops on Applications of Evolutionary Computation, Springer, pp.117-122, 2009. Article (CrossRef Link)

[12] P. Pongchairerks, "Particle swarm optimization algorithm applied to scheduling problems," Scienceasia, vol.35, no.1, pp.89-94, 2009. Article (CrossRef Link)

[13] C. Liao, C. Tseng and P. Luarn, "A discrete version of particle swarm optimization for flowshop scheduling problems,” Computers \& Operations Research, vol. 34, no.10, pp.3099-3111, 2007. Article (CrossRef Link)

[14] X. Ouyang, Y. Zhou, Q. Luo andH. Chen, “A novel discrete cuckoo search algorithm for spherical traveling salesman problem,” Applied Mathematics \& Information Sciences, vol.7, no.2, pp.777-784, 2013. Article (CrossRef Link)

[15] A. Ouaarab, B. Ahiod and X. Yang, "Discrete cuckoo search algorithm for the travelling salesman problem,” Neural Computing and Applications, vol.24, no.7-8, pp.1659-1669, 2014. Article (CrossRef Link)

[16] G. K. Jati, H.M. Manurung, et al., “Discrete cuckoo search for traveling salesman problem,” in Proc. of 7th International Conference on Computing and Convergence Technology, IEEE, pp.993-997, 2012.

[17] K. N. Abdul Rani, M. Abdul Malek and N. Siew-Chin, "Nature-Inspired Cuckoo Search Algorithm for Side Lobe Suppression in a Symmetric Linear Antenna Array,” Radio engineering, vol.21, no.3, pp.865-874, 2012.

[18] M. S. Giridhar, S. Sivanagaraju, C. V. Suresh and P. Reddy, “Analyzing the multi-objective analytical aspects of distribution systems with multiple multi-type compensators using modified cuckoo search algorithm,” International Journal of Parallel, vol.32, no.6, pp.549-571, 2017. Article (CrossRef Link)

[19] X. Liu and H. Fu, "PSO-based support vector machine with cuckoo search technique for clinical disease diagnoses,” Scientific World Journal, vol.2014, p.7, 2014. Article (CrossRef Link) 
[20] D. Giveki, H. Salimi, G. Bahmanyar and Y. Khademian, "Automatic Detection of Diabetes Diagnosis Using Feature Weighted Support Vector Machines Based on Mutual Information and Modified Cuckoo Search,” arXiv:1201.2173, 2012. Article (CrossRef Link)

[21] P. Manikandan and S. Selvarajan, "A hybrid optimization algorithm based on cuckoo search and PSO for data clustering," International Review on Computers and Software, vol.8, no.9, pp.2278-2287, 2013. Article (CrossRef Link)

[22] M. Zaw and E. Mon, "Web Document Clustering by Using PSO-Based Cuckoo Search Clustering Algorithm,” Recent Advances in Swarm Intelligence and Evolutionary Computation, pp 263-281, 2014. Article (CrossRef Link)

[23] R. Chouder and N. Benhamidouche, "New exact solutions to nonlinear diffusion equation that occurs in image processing," International Journal of Computing Science and Mathematics, vol. 10, 2019. Article (CrossRef Link)

[24] A.K. Bhandari, V.K. Singh, A. Kumar and G.K. Singh, "Cuckoo search algorithm and wind driven optimization based study of satellite image segmentation for multilevel thresholding using Kapur’s entropy,” Expert System with Application, vol.41, no.7, pp.3538-3560, 2014. Article (CrossRef Link)

[25] G. Kanagaraj, S. Ponnambalam and N. Jawahar, "A hybrid cuckoo search and genetic algorithm for reliability-redundancy allocation problems,” Computer and Industrial Engineering, vol.66, no.4, pp.1115-1124, 2013. Article (CrossRef Link)

[26] M. Behroozifar and F. Ahmadpour, "A study on spectral methods for linear and nonlinear fractional differential equations," International Journal of Computing Science and Mathematics, vol. 10, 2019. Article (CrossRef Link)

[27] S. Asghari and N. J. Navimipour, "Cloud service composition using an inverted ant colony optimisation algorithm," International Journal of Bio-Inspired Computation, vol. 13, 2019. Article (CrossRef Link)

[28] G. Kanagaraj, S. Ponnambalam, N. Jawahar and J.M. Nilakantan, "An effective hybrid cuckoo search and genetic algorithm for constrained engineering design optimization, Engineering Optimization,” Engineering Optimization, vol.46, no.10, pp.1331-1351, 2014. Article (CrossRef Link)

[29] G. Wang, L. Guo, H. Duan, L. Liu, H. Wang, and B. Wang, "A hybrid meta-heuristic DE/CS algorithm for UCAV path planning,” Scientific World Journal, vol. 2012, pp.583973, 2012. Article (CrossRef Link)

[30] B. Nancharaiah, and B.C. Mohan, "Hybrid optimization using ant colony optimization and cuckoo search in MANET routing," in Proc. of 2014 International Conference on Communications and Signal Processing (ICCSP), IEEE, pp.1729-1734, 2014. Article (CrossRef Link)

[31] E. Bjornson, E. Jorswieck, and M Debbah, "Multiobjective Signal Processing Optimization: The way to balance conflicting metrics in 5G systems," IEEE Signal Processing Magazine, vol.31, no.6, pp.14-23, 2014. Article (CrossRef Link)

[32] R. S. Parpinelli, G. F. Plichoski, R. S. Silva and P. Narloch, "A review of techniques for online control of parameters in swarm intelligence and evolutionary computation algorithms," International Journal of Bio-Inspired Computation, vol. 13, pp. 1-20, 2019. Article (CrossRef Link)

[33] Y. Liu, "Solving nonlinear system of second-order boundary value problems using a newly constructed scaling function," International Journal of Computing Science and Mathematics, vol. 10, 2019. Article (CrossRef Link)

[34] S. Negi and S. B. Singh, "Fuzzy reliability evaluation of linear m-consecutive weighted-k-out-of-r-from-n: F systems," International Journal of Computing Science and Mathematics, vol.10, 2019. Article (CrossRef Link)

[35] Z. Cui, J. Zhang, D. Wu, X. Cai, H. Wang, W. Zhang and J. Chen, "Hybrid Many-Objective Particle Swarm Optimization Algorithm for Green Coal Production Problem," Information Sciences, vol.518, pp.256-271, 2020. Article (CrossRef Link) 
[36] Z. Cui, L. Du, P. Wang, X. Cai and W. Zhang, "Malicious code detection based on CNNs and multi-objective algorithm,” Journal of Parallel and Distributed Computing, vol.129, pp.50-58, 2019. Article (CrossRef Link)

[37] Z. Cui, J. Zhang, Y. Wang, Y. Cao, X. Cai, W. Zhang and J. Chen, “A pigeon-inspired optimization algorithm for many-objective optimization problems,” SCIENCE CHINA Information Sciences, vol.62, no.7, pp.131-138, 2019. Article (CrossRef Link)

[38] S. Hanoun, S. Nahavandi, D. Creighton and H. Kull, "Solving a multi-objective job shop scheduling problem using Pareto archived cuckoo search," in Proc. of $17^{\text {th }}$ Emerging Technologies Factory Automation (ETFA), IEEE, pp.1-8, 2012. Article (CrossRef Link)

[39] M. Zhang, H. Wang, Z. Cui and J. Chen, "Hybrid multi-objective cuckoo search with dynamical local search,” Memetic Computing, vol.10, no.2, pp.199-208, 2018. Article (CrossRef Link)

[40] L. Coelho, F. Guerra and N. Batistela, "Multi-objective cuckoo search algorithm based on duffing's oscillator applied to jiles-atherton vector hysteresis parameters estimation,” IEEE Transactions on Magnetics, vol.49, no.5, pp.1745-1748, 2013. Article (CrossRef Link)

[41] Q. Wang, S. Liu and H. Wang, "Multi-objective cuckoo search for the optimal design of water distribution systems," in Proc. of International conference on civil engineering and urban planning, 2012. Article (CrossRef Link)

[42] X. Zhou, Y. Liu and B. Li, "A multi-objective discrete cuckoo search algorithm with local search for community detection in complex networks," Modern Physics Letter B, vol.30, no.07, pp.1650080, 2016. Article (CrossRef Link)

[43] Z. Wang and Y. Li, "Irreversibility analysis for optimization design of plate fin heat exchangers using a multi-objective cuckoo search algorithm," Energy Conversion and Management, vol.101, pp.126-135, 2015. Article (CrossRef Link)

[44] Z Cui, M. Zhang, and H Wang. “A hybrid many-objective cuckoo search algorithm,” Soft Computing, vol.10, no.2, pp.199-208, 2019. Article (CrossRef Link)

[45] D. H. Wolpert, and W. G. Macready, "No free lunch theorems for optimization," IEEE Transactions on Evolutionary Computation, vol. 1, no.1, pp.67-82, 1997. Article (CrossRef Link)

[46] X. Cai, X. Gao and Y. Xue, "Improved bat algorithm with optimal forage strategy and random disturbance strategy,” International Journal of Bio-inspired Computation, vol.8, no.4, pp.205-214, 2016. Article (CrossRef Link)

[47] Z. Cui, Y. Chang, J. Zhang, X. Cai and W. Zhang, "Improved NSGA-III with selection-and-elimination operator," Swarm and Evolutionary Computataion, vol.49, pp.23-33,2019. Article (CrossRef Link)

[48] K. Deb, A. Pratap, S. Agarwal and T. Meyarivan, “A fast and elitist multiobjective genetic algorithm: NSGA-II,” IEEE Transactions on Evolutionary Computation, vol.6, no.2, pp.182-197, 2002. Article (CrossRef Link)

[49] P. Wang, F. Xue, H. Li, Z. Cui, L. Xie and J. Chen, “A Multi-Objective DV-Hop Localization Algorithm Based on NSGA-II in Internet of Things,” Mathematics, vol.7, no.2, 184, 2019. Article (CrossRef Link)

[50] Y. Wang, P. Wang, J. Zhang, Z. Cui, X. Cai, J. Chen, and W. Zhang, “A Novel Bat Algorithm with Multiple Strategies Coupling for Numerical Optimization,” Mathematics, vol.7, no.2, 135, 2019. Article (CrossRef Link)

[51] M. Gong, L. Jiao, H. Du, and L. Bo, "Multiobjective immune algorithm with non-dominated neighbor-based selection,” Evolutionary Computation, vol.16, no.2, pp.225-255, 2008. Article (CrossRef Link)

[52] C. A. Coello, and M. S. Lechuga, "MOPSO: A proposal for multiple objective particle swarm optimization,” in Proc. of the IEEE Congress on Evolutionary Computation, pp.1051-1056, 2002. Article (CrossRef Link)

[53] C. A. Coello, and N. C. Cortes, "Solving multiobjective optimization problems using an artificial immune system,” Genetic Programming and Evolvable Machines, vol. 6, no.2, pp. 163-190, 2005. Article (CrossRef Link) 
[54] E. Zitzler, K. Deb, and L. Thiele, "Comparison of multiobjective evolutionary algorithms: Empirical results,” Evolutionary computation, vol.8, no. 2, pp.173-195, 2000. Article (CrossRef Link)

[55] K. Deb, L. Thiele, M. Laumanns, and E. Zitzler, "Scalable test problems for evolutionary multiobjective optimization,” Evolutionary Multiobjective Optimization. Theoretical Advances and Applications, pp.105-145, 2005. Article (CrossRef Link)

[56] R. Cheng, M. Li, Y. Tian, X. Zhang, S. Yang, Y. Jin and X. Yao, "A benchmark test suite for evolutionary many-objective optimization,” Complex \& Intelligent Systems, vol.3, no.1, pp.67-81, 2017. Article (CrossRef Link)

[57] H. Yang and T. Marzetta, "Total energy efficiency of cellular large scale antenna system multiple access mobile networks," in Proc. of 2013 IEEE online conference on green communications, pp.27-32, 2013. Article (CrossRef Link)

[58] G. Auer, V. Giannini, C. Desset, "How much energy is needed to run a wireless network?," IEEE wireless communications, vol. 18, no.5, pp.40-49, 2011. Article (CrossRef Link)

[59] E. Bjornson, L. Sanguinetti and J. Hoydis, "Optimal Design of Energy-Efficient Multi-User MIMO Systems: Is Massive MIMO the Answer?," IEEE Transactions on Wireless Communications, vol.14, no.6, pp.3059-3075, 2015. Article (CrossRef Link)

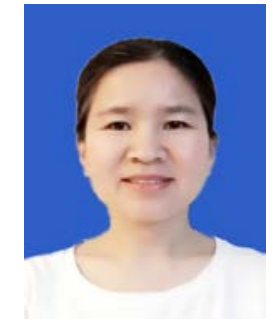

Junyan Wang received the M.S degree from Taiyuan University of Science and Technology in 2008. Currently, she is a teacher at Taiyuan University of Science and Technology. Her research interests include intelligence computation and its applications. 